\title{
Jahn-Teller Effect in Ultrafine Copper Ferrite Particles
}

\author{
M. YOKOYAMA ${ }^{1,}$, A. NAKAMURA ${ }^{2}$, T. SATO ${ }^{3}$, and K. HANEDA ${ }^{4}$ \\ 1) Faculty of Science and Technology, Keio University \\ 3-14-1 Hiyoshi, Kohoku-ku, Yokohama, Kanagawa 223, Japan \\ 2) Tokin Corporation \\ 6-7-1 Koriyama, Sendai, Miyagi 982, Japan \\ 3) Faculty of Engineering, Tokyo Engineering University \\ 1404-1 Katakura, Hachioji, Tokyo 192, Japan \\ 4) School of Science and Technology, Ishinomaki Senshu University \\ 1 Minamisakai Shinmito, Ishinomaki, Miyagi 986, Japan.
}

\begin{abstract}
The magnetic properties of ultrafine copper ferrite particles have been investigated, and to examine the possibility of enhanced coercive force in ultrafine particles by Jahn-Teller effect. Ultrafine copper ferrite particles prepared by coprecipitation have been heated at various temperatures. X-ray diffaction patterns indicate that the crystal structure of ultrafine copper ferrite particles obtained by heating at a temperature above $\sim 400^{\circ} \mathrm{C}$ is tetragonal with the axial ratio $(c-a) / a$ of $\sim 5.8 \%$, which is nearly equivalent to that of the bulk material, while that of the ultrafine particles obtained by heating at a temperature below $\sim 300^{\circ} \mathrm{C}$ is cubic. The maximum coercive force obtained in this work has been $\sim 1500$ Oe at heating temperature of $\sim 700^{\circ} \mathrm{C}$. It has been believed that Jahn-Teller effect obviously occur in ultrafine copper ferrite particles with the particle size of 12 40 nm The enhanced coercive force can be mainly attributed to uniaxial magnetic anisotropy produced by the crystal distortion.
\end{abstract}

\section{INTRODUCTION}

Jahn-Teller effect for bulk copper ferrite $\left(\mathrm{CuFe}_{2} \mathrm{O}_{4}\right)$ is explained by the phenomenon that the crystal structure is transformed from cubic to tetragonal by slow cooling from above the transition temperature of $360^{\circ} \mathrm{C}[1]$. Copper ions cause Jahn-Teller effect in partial inverse $\mathrm{CuFe}_{2} \mathrm{O}_{4}$. The crystal distortion by Jahn-Teller effect depends on the copper distribution [2]. The copper ions occupancy of 0.25 at the tetrahedral sites is a critical value to cause the crystal distortion [1]. The magnetization increases with increasing occupancy of copper ions at the tetrahedral sites. Thus, the magnetization of the cubic $\mathrm{CuFe}_{2} \mathrm{O}_{4}$ is larger than that of the tetragonal $\mathrm{CuFe}_{2} \mathrm{O}_{4}$.

The coprecipitation method has been used to obtain ultrafine spinel ferrite particles in alkaline aqueous solution at a temperature below $100^{\circ} \mathrm{C}$ [3]. When ultrafine $\mathrm{CuFe}_{2} \mathrm{O}_{4}$ particles are prepared by the coprecipitation, the cation distribution in the ultrafine particles would be different from that in the bulk material. If Jahn-Teller effect occurs in ultrafine $\mathrm{CuFe}_{2} \mathrm{O}_{4}$ particles which behave as a single domain, an enhanced coercive force can be expected due to the magnetic anisotropy caused by the crystal distortion. We have investigated the magnetic properties of ultrafine $\mathrm{CuFe}_{2} \mathrm{O}_{4}$ particles, and discuss the possibility of enhanced coercive force in ultrafine particles by Jahn-Teller effect.

*present address: School of Science and Technology, Ishinomaki Senshu University, 1 Minamisakai Shinmito, Ishinomaki, Miyagi 986, Japan.

\section{EXPERIMENTAL PROCEDURE}

Ultrafine $\mathrm{CuFe}_{2} \mathrm{O}_{4}$ particles were prepared with the following procedure: first, copper (II) chloride solution (0.1 mol/l) and iron (III) chloride solution $(0.2 \mathrm{~mol} / \mathrm{l})$ were prepared separately, and were mixed. Sodium hydroxide solution $(3 \mathrm{~mol} / \mathrm{l})$ was added to the mixed solution until a $\mathrm{pH}$ of 13 was attained. The resultant solution was boiled at $100^{\circ} \mathrm{C}$ for $2 \mathrm{hr}$. The product was washed with deionized water, filtered, and dried at $60^{\circ} \mathrm{C}$. Finally, the dried sample (ultrafine $\mathrm{CuFe}_{2} \mathrm{O}_{4}$ particles) prepared by coprecipitation have been heated at various temperatures for $2 \mathrm{hr}$, and slowly cooled to room temperature.

The crystal structures of the particles were determined by $\mathrm{x}$-ray diffraction $(\mathrm{XRD})$. We evaluated the average particle size from full width at half maximum of $x$-ray diffraction line by using Scherrer's formula. Magnetization curves at $77 \mathrm{~K}$ and $300 \mathrm{~K}$ were measured in a maximum magnetic field of 15 kOe using a vibrating sample magnetometer.

\section{RESULTS AND DISCUSSION}

Figure 1 shows XRD patterns, taken using Mo-K $\alpha$ radiation, of ultrafine $\mathrm{CuFe}_{2} \mathrm{O}_{4}$ particles. The crystal structure of the ultrafine particles obtained by heating at a temperature above $-400^{\circ} \mathrm{C}$ is tetragonal, while that of the ultrafine particles obtained by heating at a temperature below $\sim 300^{\circ} \mathrm{C}$ is cubic. XRD patterns suggest the formation of ultrafine particles. As shown in Fig. 2, the average particle size gradually increases with increasing a heating temperature up to $\sim 700^{\circ} \mathrm{C}$, and drastically increases above $\sim 700^{\circ} \mathrm{C}$. Ultrafine 


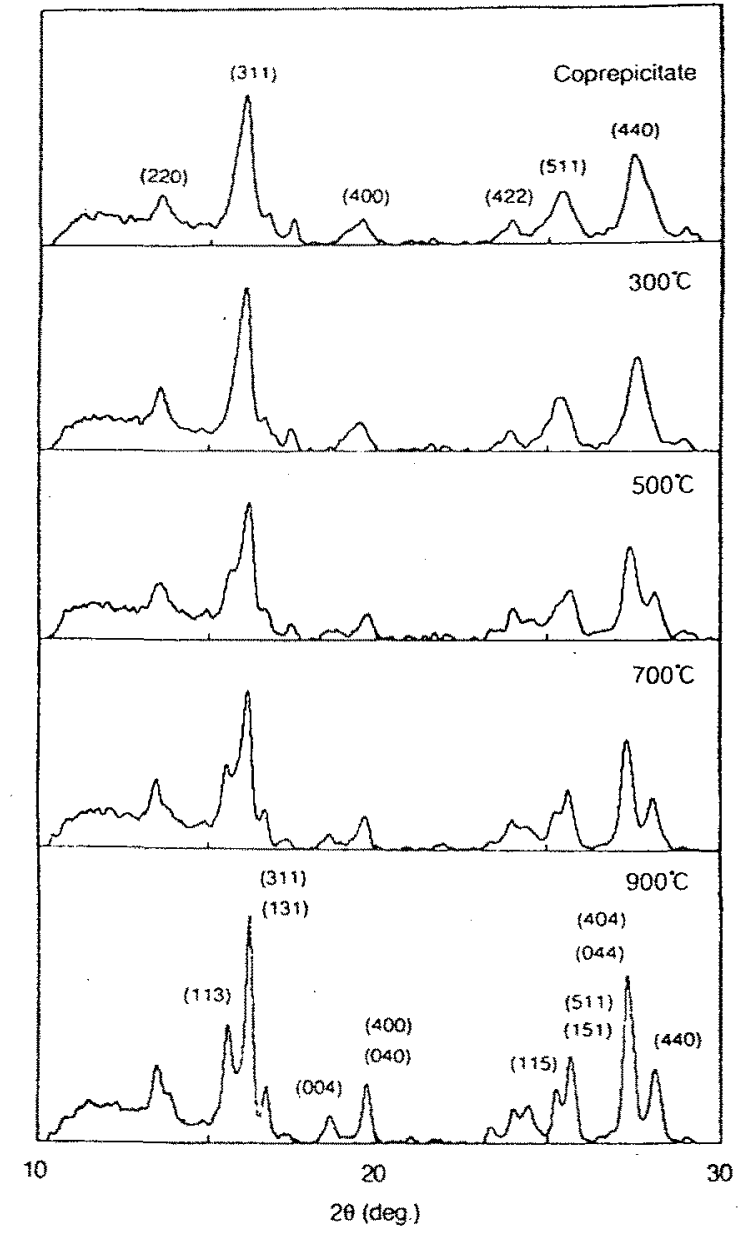

Fig. $1 \mathrm{X}$-ray diffraction patterns, taken using Mo-K $\alpha$ radiation, of ultrafine $\mathrm{CuFe}_{2} \mathrm{O}_{4}$ particles obtained by heating at various temperatures.

$\mathrm{CuFe}_{2} \mathrm{O}_{4}$ particles have the particle size of $12 \sim 40 \mathrm{~nm}$.

Axial ratio $(c-a) / a$ of ultrafine $\mathrm{CuFe}_{2} \mathrm{O}_{4}$ particles for various heating temperatures is shown in Fig. 3. The ultrafine particles by heating at a temperature below $-300^{\circ} \mathrm{C}$ have the $(c-a) / \alpha$ of $\sim 0$, because the crystal structure of the ultrafine particles is cubic. The $(c-a) / a$ of ultrafine $\mathrm{CuFe}_{2} \mathrm{O}_{4}$ particles increases with increasing a heating temperature above $-400^{\circ} \mathrm{C}$. Ultrafine $\mathrm{CuFe}_{2} \mathrm{O}_{4}$ particles by heating at a temperature above $-600^{\circ} \mathrm{C}$ have the $(c-a) / a$ of $\sim 5.8 \%$, which is nearly equivalent to that of the bulk material. Therefore, the above results suggest that Jahn-Teller effect obviously occur in ultrafine $\mathrm{CuFe}_{2} \mathrm{O}_{4}$ particles obtained by heating at a temperature above $-400^{\circ} \mathrm{C}$.

Magnetizations in a magnetic field of $15 \mathrm{kOe}$ of ultrafine $\mathrm{CuFe}_{2} \mathrm{O}_{4}$ particles for various heating temperatures are shown

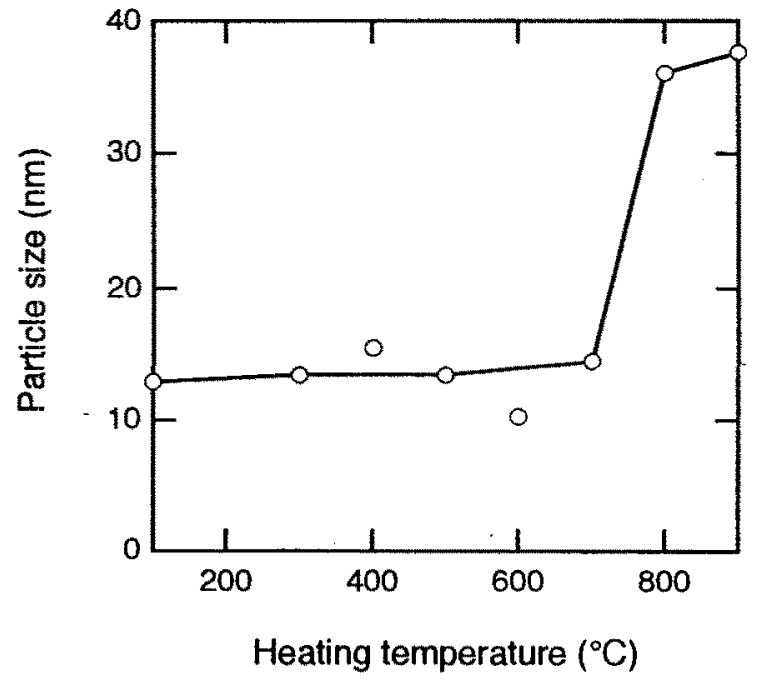

Fig. 2 The average particle size for various heating temperatures. The average particle size has been evaluated from full width at half maximum of XRD pattern line by using Scherrer's formula.

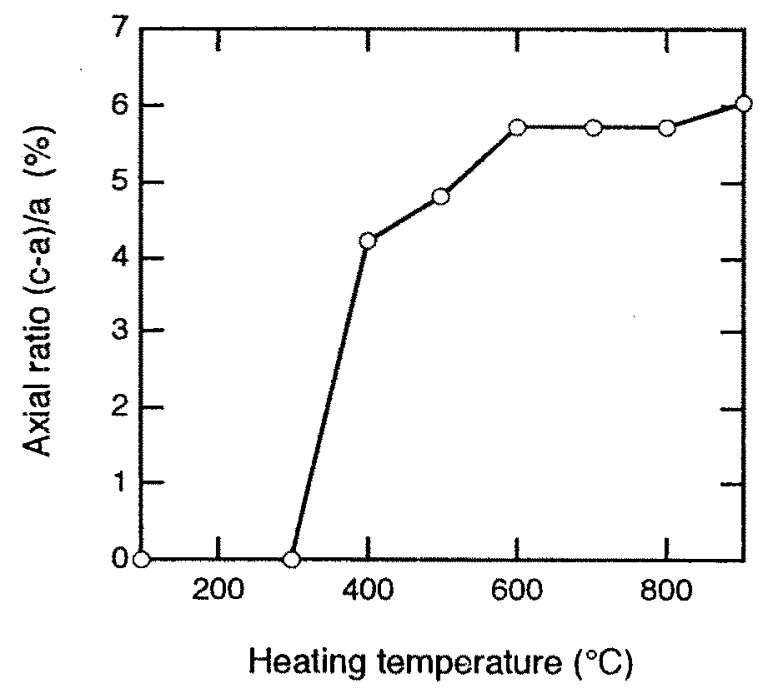

Fig. 3 Axial ratio $(c-a) / a$ of ultrafine $\mathrm{CuFe}_{2} \mathrm{O}_{4}$ particles for various heating temperatures. The ultrafine particles by heating at a temperature above $600^{\circ} \mathrm{C}$ have the $(c-a) / a$ of $-5.8 \%$, which is nearly equivalent to that of the bulk material.

in Fig. 4. Magnetizations at $77 \mathrm{~K}$ of ultrafine $\mathrm{CuFe}_{2} \mathrm{O}_{4}$ particles shows the small depression at heating temperatures from $\sim 300$ to $\sim 600^{\circ} \mathrm{C}$. Let us first consider the magnetization of ultrafine $\mathrm{CuFe}_{2} \mathrm{O}_{4}$ particles obtained by heated at a temperature below $\sim 300^{\circ} \mathrm{C}$. As the crystal structure of 


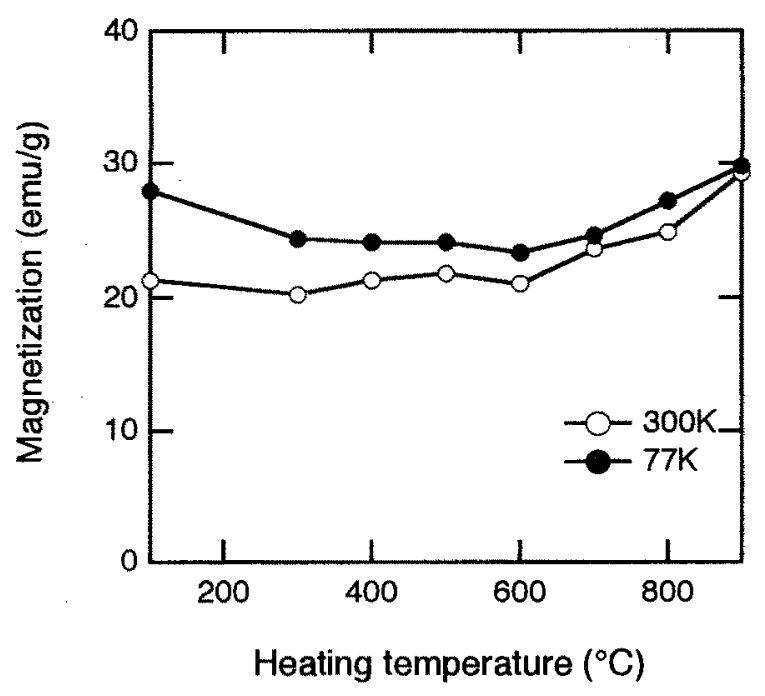

Fig. 4 Magnetizations in a magnetic field of $15 \mathrm{kOe}$ of ultrafine $\mathrm{CuFe}_{2} \mathrm{O}_{4}$ particles for various heating temperatures.

ultrafine $\mathrm{CuFe}_{2} \mathrm{O}_{4}$ particles obtained by heating at a temperature below $-300^{\circ} \mathrm{C}$ is cubic, the crystal distortion does not occur in the ultrafine particles. Thus, the occupancy of copper ions at the tetrahedral sites would be more than 0.25 [1], which is a critical value to cause the crystal distortion by Jahn-Teller effect. Ultrafine $\mathrm{CuFe}_{2} \mathrm{O}_{4}$ particles have a usual spin arrangement of ferrimagnetic spinel ferrite, i.e., the antiparallel arrangement of the spins at the tetrahedral and octahedral sites. When ultrafine $\mathrm{CuFe}_{2} \mathrm{O}_{4}$ particles have high occupancy of copper ions at tetrahedral sites, the magnetization should be larger than that of the ultrafine particles with low occupancy. Therefore, the magnetizations of ultrafine $\mathrm{CuFe}_{2} \mathrm{O}_{4}$ particles prepared by coprecipitation are larger compared with that of the ultrafine particles obtained by heating at a temperature of $\sim 300^{\circ} \mathrm{C}$.

Then, let us consider the magnetization of ultrafine $\mathrm{CuFe}_{2} \mathrm{O}_{4}$ particles obtained by heating at a temperature above $-600^{\circ} \mathrm{C}$. We assume that the magnetic structure of ultrafine $\mathrm{CuFe}_{2} \mathrm{O}_{4}$ particles consists of magnetically inactive or spin canting surface layer and usual magnetic core. Then, the magnetization should increase with increasing particle size in ultrafine particles, because of the relative decrease of the effects of surface layer. We note that the average particle size drastically increases with increasing a heating temperature above $\sim 700^{\circ} \mathrm{C}$. Therefore, the remarkable increase of the particle size would cause the increase of the magnetizations of ultrafine $\mathrm{CuFe}_{2} \mathrm{O}_{4}$ particles obtained by heating at a temperature above $-600^{\circ} \mathrm{C}$.

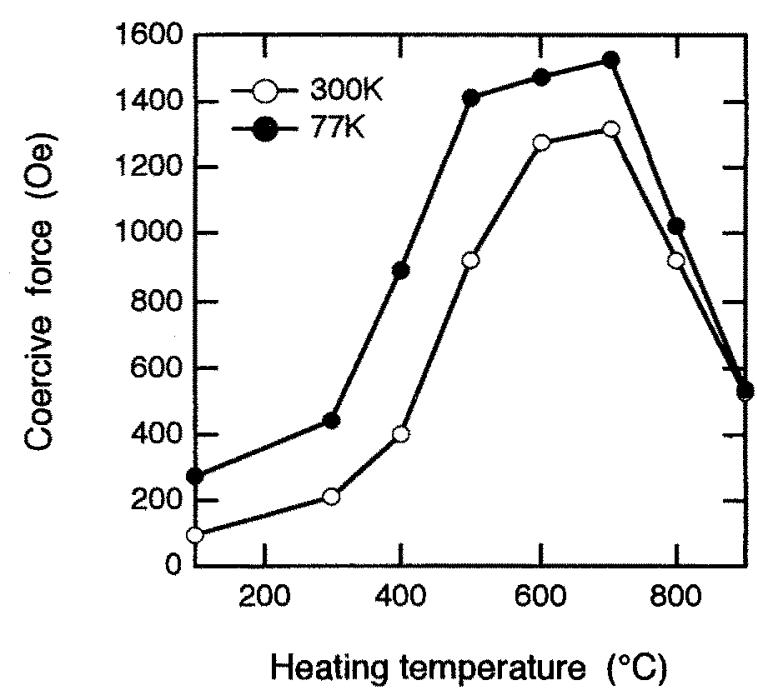

Fig. 5 Coercive force ofultrafine $\mathrm{CuFe}_{2} \mathrm{O}_{4}$ particles at various heating temperatures. The maximum coercive forces at $77 \mathrm{~K}$ and $300 \mathrm{~K}$ has been $\sim 1500$ and $\sim 1300$ Oe respectively at the heating temperature of $-700^{\circ} \mathrm{C}$.

Coercive force of ultrafine $\mathrm{CuFe}_{2} \mathrm{O}_{4}$ particles for various heating temperatures are shown in Fig. 5. Coercive force of ultrafine $\mathrm{CuFe}_{2} \mathrm{O}_{4}$ particles remarkably increases at a heating temperature of $\sim 400^{\circ} \mathrm{C}$, at which the crystal distortion by Jahn-Teller effect occurs in this work. The maximum coercive forces at $77 \mathrm{~K}$ and $300 \mathrm{~K}$ has been $\sim 1500$ and $\sim 1300$ Oe respectively at a heating temperature of $\sim 700^{\circ} \mathrm{C}$. The drastic increase of the average particle size may contributeto the decrease of coercive force of ultrafine $\mathrm{CuFe}_{2} \mathrm{O}_{4}$ particles obtained by heating at a temperature above $-800^{\circ} \mathrm{C}$. The enhanced coercive force of ultrafine $\mathrm{CuFe}_{2} \mathrm{O}_{4}$ particles obtained by heating temperatures from -400 to $\sim 700^{\circ} \mathrm{C}$ should be attributed to the crystal distortion by Jahn-Teller effect and the single domain behavior.

In conclusion, it has been believed that Jahn-Teller effect obviously occur in ultrafine $\mathrm{CuFe}_{2} \mathrm{O}_{4}$ particles with the particle size of $12 \sim 40 \mathrm{~nm}$. The enhanced coercive force can be mainly attributed to uniaxial magnetic anisotropy produced by the crystal distortion.

\section{REFERENCES}

[1] H. Ohnishi, T. Teranishi, and S. Miyahara, J. Phys. Soc. Japan 14, 106 (1959).

[2] H. Ohnishi, and T. Teranishi, J. Phys. Soc. Japan 16, 35 (1961).

[3] T. Sato, M. Sugihara, and M. Saito, J. Chem. Soc. Jpn. Ind. Chem. Sect. 65, 1748 (1962). 